\title{
A GESTÃo dEMOCRÁTICA E A FORMAÇÃO PARA A CIDADANIA: COMPROMISSO SOCIAL E POLÍTICO
}

\section{THE DEMOCRATIC FORMATION TO CITIZENSHIP: SOCIAL AND POLITIC COMMITMENT}

\author{
Morgana Marcelino de Souza ${ }^{1}$ \\ Maria Aparecida da Silva Méllo²
}

\begin{abstract}
RESUMO: A gestão democrática na escola possui caráter de grande significado, pois é condição necessária para o desenvolvimento de uma educação de qualidade. Isso se dá devido ao fato da gestão democrática, em seus princípios, ensejar a participação efetiva da comunidade, dando oportunidade para que haja envolvimento e comprometimento de todos, numa perspectiva de educação para a formação cidadã. Em razão do exposto, as ações de planejamento constituem-se em possibilidade concreta para consecução de tais objetivos, visto que entende-se o projeto político-pedagógico como instrumento de gestão democrática, fomentando debates e definindo ações coletivas, voltadas às necessidades da escola e dos alunos. Para fundamentar o tema, realizou-se um estudo teórico sobre a função social da escola, a gestão democrática e o projeto político-pedagógico, cujo objetivo principal foi analisar o papel da gestão democrática na formação para a cidadania. Realizou-se também uma pesquisa de campo com três gestores da rede pública municipal da cidade de Criciúma para verificar quais ações são desenvolvidas para o cumprimento da função social; analisar a percepção dos diretores acerca do cumprimento da função social; compreender o processo de construção da gestão democrática e identificar os instrumentos utilizados. Partindo desta premissa, constatou-se ao final da pesquisa indícios de gestão com aporte técnico e burocrático, sem a preocupação com o desenvolvimento para a cidadania. Nessa perspectiva, entende-se a necessidade das escolas pesquisadas refletirem sobre o papel da gestão democrática como instrumento para o cumprimento da função social, no sentido de colaborar com ensino de qualidade e formação cidadã.
\end{abstract}

PALAVRAS-CHAVE: Função social da escola. Gestão democrática. Projeto políticopedagógico.

ABSTRACT: The democratic management at a school is something with great significance, because it is necessary for a quality education development. This happens due to the fact that the democratic management, in its principles, enables the community

\footnotetext{
${ }^{1}$ Acadêmica do curso de Pedagogia/UNESC. E-mail: morganamarsou@gmail.com

${ }^{2}$ Orientadora. Mestra em Educação. E-mail: msm@unesc.net

Saberes Pedagógicos, Criciúma, v. 3, n³, Edição Especial 2019.- Curso de Pedagogia - UNESC
} 
effective participation, giving the opportunity for everyone involvement and commitment, in a education perspective for a citizen training. Because of that, the planning actions are concrete possibilities to accomplish such objectives, since the political pedagogic project is understood as a democratic management instrument, promoting debates and defining collective actions, focused on the school and students necessities. To support the theme, it was carried out a theoretical study about the school social function, the democratic management and the political pedagogic project, whose main objective was to analyze the democratic management role in the citizen training. It was also carried out a field research with three managers from the municipal public network in Criciúma municipality, to verify which actions are developed for the social function fulfillment; to analyze the principals' perceptions on the social function fulfillment; to understand the democratic management construction process and identify the used instruments. From this premise, it was found at the end of the research, indications of a management with technical and bureaucratic contribution, with no concern about the development for the citizenship. In this perspective, it is seen the necessity of the researched schools reflect about the democratic management role as instrument for the social function fulfillment, in the sense of collaborating with teaching quality and citizen training.

KEYWORDS: School's social function. Democratic management. Political pedagogical project.

\section{INTRODUÇÃO}

Durante toda a jornada acadêmica e no convívio com profissionais do meio educacional um dos assuntos mais recorrentes trata do papel da escola na formação do cidadão e de que maneira a gestão democrática contribui com este propósito. Assim, entende-se a gestão democrática como possibilidade concreta para a consecução da função social da escola à medida que ela promove a participação efetiva de toda comunidade educativa nas reflexões e nas ações que venham favorecer a formação dos cidadãos em sujeitos emancipados e capazes de colaborar na transformação da sociedade.

Nessa mesma direção, o projeto político-pedagógico assume uma grande representatividade como um dos canais de participação, pois as decisões passam a ser coletivas e as ações pensadas e articuladas em razão das necessidades de aprendizagem dos alunos e da consolidação da autonomia da escola. Por ser a escola parte inalienável da vida em sociedade e não um estabelecimento destinado exclusivamente ao ensino de conteúdos curriculares previamente formatados, coloca-se esta como agente determinante 
na formação de indivíduos capazes de exercer plenamente sua cidadania. Diante dessa premissa é que se estabelece a importância da pesquisa do tema apresentado.

Considerando que a gestão escolar determina os caminhos da escola e influencia a formação daqueles que nela se inserem, compreender como as práticas de gestão escolar afetam o cumprimento da função social da escola e quais os impactos da falta desta na formação da cidadania constitui-se em um dos objetos desta investigação.

Para dar conta dos aspectos acima mencionados, o objetivo geral desta investigação é analisar o papel da gestão democrática na formação para a cidadania. Para o alcance deste, a pesquisa foi desdobrada nos seguintes objetivos específicos: verificar quais ações são desenvolvidas na escola para o cumprimento da sua função social; analisar a percepção dos diretores escolares acerca do cumprimento da função social da escola e correspondência com a sua prática gestora; compreender o processo de construção da gestão democrática da escola, seus instrumentos e elementos básicos; identificar os elementos e instrumentos utilizados pela gestão escolar na formação para a cidadania.

Para que esses objetivos sejam atingidos, utilizou-se como procedimentos metodológicos a pesquisa exploratória do tipo descritiva e de abordagem qualitativa, com objetivo de proporcionar maior familiaridade com o assunto pesquisado. Tendo em vista alcançar os objetivos anteriormente citados, foram realizados estudos bibliográficos sobre a função social, assim como sobre práticas de gestão democrática e o projeto políticopedagógico como instrumento da gestão democrática. Foi também realizada uma pesquisa com gestores de três escolas da rede pública municipal da cidade de Criciúma/SC.

\section{FUNÇÃO SOCIAL DA ESCOLA E FORMAÇÃO CIDADÃ}

A temática "função social da escola" tornou-se parte fundamental nos debates sobre a relação sociedade/escola, na perspectiva de um processo educativo voltado transformação social. Partindo dessa questão, na qual evidencia-se a relevância social da educação, torna-se necessário a compreensão da escola.

Segundo Saviani (1997), atualmente, a escola possui uma estrutura centralizada, não sendo possível separar educação, escola e sociedade. Porém, realizando Saberes Pedagógicos, Criciúma, v. 3, nº3, Edição Especial 2019.- Curso de Pedagogia - UNESC 
uma breve análise da origem da palavra escola percebe-se que não desempenhava um papel crucial na sociedade, nem monopolizava as relações de ensino, pois nos primórdios o homem se educava à medida que trabalhava, as modificações da maneira como agia e existia ocorriam em ações coletivas (SAVIANI, 1997).

De acordo com os estudos de Saviani (1997), a escola tem definição grega que significa estar ligado ao lugar do ócio. Em outras palavras, aqueles que não precisavam trabalhar dedicavam-se ao lazer, palavra esta denominada escola.Com o tempo a escola foi obtendo diferentes significados. No Renascimento, segundo Aranha (2006), a burguesia atribui a esta unidade grande importância.

Ainda na visão de Aranha (2006, p. 125):

Educar torna-se questão de moda e uma exigência conforme a nova concepção de ser humano. [...] Enquanto os mais ricos ou da alta nobreza continuavam a ser educados por preceptores em seus próprios castelos, a pequena nobreza e a burguesia também queriam educar seus filhos e os encaminhavam para a escola, na esperança de melhor prepará-los para a liderança e a administração da política e dos negócios.

Compreende-se que as relações entre as atribuições competentes às escolas e o momento histórico-social são interdependentes. Saviani (1997) ressalta que a escola só é compreendida a partir do momento em que há desenvolvimento histórico da sociedade. A educação é caracterizada como uma atividade indispensável do ser humano, a qual se inicia praticamente com a origem do homem.

Saviani (1997) cita que o homem apenas constitui-se como um animal diferenciado, devido ao fato de não se adaptar à natureza, mas sim adaptar a natureza a si, pois o homem produz sua própria existência, agindo sobre a natureza e transformando-a. Para o autor, na sociedade primitiva a educação acontecia com a própria vida, pois viviase produzindo a própria existência, ou seja, em outras palavras, com os erros e acertos, as experiências que obtinham resultados satisfatórios eram conservados e as demais substituídas, compondo dessa forma o acervo da cultura humana.

Deposita-se na escola toda a esperança para a transformação da sociedade, ou seja, a escola envolve uma trajetória de imensa responsabilidade, indicada como solucionadora de grandes problemas, conflitos e injustiças. Diante desta posição, sabe-se a Saberes Pedagógicos, Criciúma, v. 3, nº3, Edição Especial 2019.- Curso de Pedagogia - UNESC 
necessidade que a escola tem de possuir bem definido perante a sociedade o seu papel, atribuições, funções e competências, de tal modo que não desempenhe ações diferentes de sua finalidade, deixando de cumprir com seus reais objetivos, muitos dos quais estão previstos em lei.

De acordo com a legislação vigente, a escola brasileira possui princípios a serem seguidos, tendo assim que se enquadrar nestes. Com base na Constituição Federal, Art.206, incisos I ao IV, tem-se por princípios da Educação Nacional:

I - Igualdade de condições para acesso e permanência na escola;

II - Liberdade de aprender, ensinar, pesquisar e divulgar o pensamento, a arte e o saber;

III - Pluralismo de ideias e de concepções pedagógicas, coexistência de instituições públicas e privadas de ensino;

IV - Gratuidade do ensino público em estabelecimentos oficiais (BRASIL, 1988).

Destaca-se que os princípios supramencionados são ratificados e expandidos nos incisos do Art. $3^{\circ}$ da Lei $N^{\circ}$ 9.394/96:

I - Igualdade de condições para o acesso e permanência na escola;

II - Liberdade de aprender, ensinar, pesquisar e divulgar a cultura, o pensamento, a arte e o saber;

III - Pluralismo de ideias e de concepções pedagógicas;

IV - Respeito à liberdade e apreço à tolerância;

V - Coexistência de instituições públicas e privadas de ensino;

VI - Gratuidade do ensino público em estabelecimento oficial;

VII - Valorização do profissional da educação escolar;

VIII - Gestão democrática do ensino público, na forma desta Lei e da legislação dos sistemas de ensino;

IX - Garantia de padrão de qualidade;

$X$ - Valorização da experiência extra-escolar;

XI - Vinculação entre educação escolar, o trabalho e as práticas sociais (BRASIL, 1996).

A instituição escolar possui como principal função a socialização do saber sistematizado, ou seja, a função de educar sistematicamente. Saviani (1997) cita que é fundamental que a escola resgate a sua importância e com isso reorganize todo o trabalho educativo, não esquecendo de considerar o saber sistematizado, pois é a partir dele que se define a especificidade da educação escolar. 


\section{SABERES PEDAGÓGICOS}

Revista do Curso de Graduaçāo de Pedagogia - Unesc

ISSN 2526-4559

Conforme a Lei $\mathrm{N}^{\circ}$ 9.394/96, Art.32, os objetivos do Ensino Fundamental de nove anos a serem alcançados são:

I - O desenvolvimento da capacidade de aprender, tendo como meios básicos o pleno domínio da leitura, da escrita e do cálculo;

II - A compreensão do ambiente natural e social, do sistema político, da tecnologia, das artes e dos valores em que se fundamentam a sociedade;

III - O desenvolvimento da capacidade de aprendizagem, tendo em vista a aquisição de conhecimento e habilidades e a formação de atitudes e valores;

IV - O fortalecimento dos vínculos de família, dos laços de solidariedade humana e de tolerância recíproca em que se assenta a vida social (BRASIL, 1996).

Segundo a lei supramencionada, a escola não se compromete apenas com a transmissão do conhecimento, também deve se preocupar com o desenvolvimento das atitudes, habilidades e valores. De acordo com a legislação apontada, a escola além de comprometer-se com a aquisição de conhecimentos deve se preocupar também com o desenvolvimento de habilidades, atitudes e valores. Entende-se que a função social da escola deve estar ligada diretamente à formação integral dos sujeitos, levando-os a constituir-se em cidadãos reflexivos e críticos, capazes de intervir no meio social de modo construtivo e transformador.

Mello (2005) complementa afirmando que é de suma importância para a formação de todo e qualquer ser humano o desenvolvimento e domínio tecnológico e as suas qualificações nas formas de trabalho. Destaca-se que as atividades, sejam elas individuais ou coletivas, cada vez mais exigirão flexibilidade das pessoas envolvidas, bem como maior iniciativa. "[...] a formação de competências sociais, como liderança, iniciativa, capacidade de tomar decisões, autonomia no trabalho, habilidade de comunicação, constituem novos desafios educacionais (MELLO, 2005, p.34).”

A escola ainda deve, segundo Mello (2005), preparar cada indivíduo para saber agir com os meios de comunicação existentes, tendo como intuito agilizar as informações, filtrá-las e utilizá-las contribuindo com o desenvolvimento econômico.

A educação por si só não assegura a justiça social, o fim da violência, a erradicação da discriminação social e o respeito ao meio ambiente, no entanto, trabalha em prol do desenvolvimento integral do cidadão, tornando a sociedade mais igualitária, solidária e integrada (MELLO,2005).

Saberes Pedagógicos, Criciúma, v. 3, n³, Edição Especial 2019.- Curso de Pedagogia - UNESC 
Partindo desta premissa, entende-se que um dos pilares indispensáveis da educação é a contribuição para a formação cidadã crítica emancipadora. Assim que o sujeito domina os meios tecnológicos e de comunicação passa a entender e refletir sobre a própria interferência no meio cultural, além de buscar e ter acesso ao conhecimento de diversos assuntos, sendo assim competente o suficiente para entender seu entorno social, agindo, defendendo e transformando seus interesses.

A palavra cidadania mostra-se presente em diversos textos e documentos oficiais que norteiam a educação no Brasil. De acordo com a Constituição Federal de 1988, art. $1^{\circ}$, inciso II, um dos fundamentos da República Federativa Brasileira é a cidadania, no qual aborda-se a importância do tema. Ainda de acordo com a Constituição Federal, a educação é um direito de todo e qualquer cidadão, além disso, a educação é um dever do Estado e da família, pois necessita-se também a colaboração destes, visando preparar o aluno para o exercício da cidadania e a qualificá-lo para o trabalho (BRASIL, 1998).

Conforme a lei supramencionada, Art. 22, a Educação Nacional Básica está voltada para a cidadania, define-se como educação básica o ensino infantil, fundamental e médio. A lei ainda complementa afirmando que a educação básica tem por objetivo desenvolver e promover meios para o progresso no trabalho, estudos posteriores e em seus exercícios com a cidadania.

Salienta-se que a escola tem uma função essencial no crescimento e na construção da cidadania, porém para tanto é necessário que tenha claro qual é o seu papel e objetivos, pois dessa forma estará comprometida com a formação cidadã e cumprirá com os anseios da sociedade, sem deixar de cumprir com a sua função perante os cid adãos.

A força do cidadão e a cidadania devem estar presentes na comunidade para que se torne possível a luta por condições dignas, sejam estas de moradia, segurança, saúde, direito de manifestação ou simplesmente a participação. Isso remete aos comentários de Covre (1998, p. 10):

Só existe cidadania se houver a prática da reivindicação, da apropriação de espaços, da pugna para fazer valer os direitos do cidadão. Neste sentido, a prática da cidadania pode ser a estratégia, por excelência, para a construção de uma sociedade melhor. Mas o primeiro pressuposto dessa prática é que esteja

Saberes Pedagógicos, Criciúma, v. 3, n³ 3, Edição Especial 2019.- Curso de Pedagogia - UNESC 


\section{SABERES PEDAGÓGICOS}

Revista do Curso de Graduaçūo de Pedagogia - Unesc

ISSN 2526-4559

assegurado o direito de reivindicar os direitos, e que o conhecimento deste se estenda cada vez mais a toda a população.

O cidadão deve fazer sua própria história, lutar e fazer valer sua força e os seus direitos. Na opinião de Bordignon e Gracindo (2001), o cidadão deve ser crítico o suficiente e condutor das informações e do conhecimento, além disso ser produtor da tecnologia, garantir o bem comum, não aceitando injustiças de modo passivo.

Arroyo (2010) destaca que educar o ser humano para ser posteriormente cidadão não garante que ele será incluso no âmbito social, mas sim, agindo desta forma, justificará a exclusão do indivíduo na cidadania da classe social. O autor supramencionado ainda complementa afirmando que é necessário analisar se "[...] a relação entre educação e cidadania está contribuindo para garantir a cidadania dos trabalhadores ou, ao contrário, está contribuindo para justificar e racionalizar a sua exclusão (ARROYO, 2010, p. 39).”

Um tópico pertinente a esta abordagem é de que o povo é excluído da cidadania por falta de formação e informação. Isso remete aos comentários de Arroyo (2000), o qual cita que uma maneira de colocar a relação cidadania e educação no seu devido lugar é quebrando o paradigma de que a educação é uma solução para a condição de cidadão e de sujeito político.

Arroyo (2010) destaca que a educação não é e nem deve ser uma pré-condição da democracia e da participação, todavia, é fruto da expressão do processo de constituição. Com este enfoque da educação, começa-se a superar os conceitos tradicionais. O que leva aos comentários de Bordignon e Gracindo, que alegam que a educação vai além de preparar os indivíduos para os exercícios da cidadania, mas pode ser definida como a construção da cidadania.

Para Bordignon e Gracindo (2001), é crucial mencionar que a democracia e a cidadania são conceitos inseparáveis, pois sem um não é possível viabilizar o outro, ou seja, sem a democracia não existiria espaço para os cidadãos, mas sim apenas para os governados.

Em suma, todos os indivíduos devem participar das ações cidadãs, não apenas os que estão envolvidos no âmbito escolar, e a escola tem um papel fundamental, como instituição social, para contribuir no crescimento e na construção da cidadania, Saberes Pedagógicos, Criciúma, v. 3, nº3, Edição Especial 2019.- Curso de Pedagogia - UNESC 
possibilitando conhecimentos, informações, práticas vivenciais e ferramentas que favoreçam a formação cidadã (SAVIANI, 1997).

\section{GESTÃO DEMOCRÁTICA: ASPECTOS CONCEITUAIS E HISTÓRICOS}

O conceito de gestão escolar é relativamente recente e de muita importância na medida em que desejamos uma escola que forme verdadeiros cidadão, comprometidos com a sociedade em que vivem.

Na formulação de Luck (2002), para que uma escola possa obter o êxito, todos devem caminhar juntos rumo aos mesmos objetivos, sendo indispensável o trabalho de toda comunidade educativa nos processos de gestão, na construção do projeto políticopedagógico e compartilhamento do poder. O autor ainda menciona que o termo gestão já está interligado com participação, ou seja, quando se remete à palavra gestão automaticamente está se falando em trabalho em equipe, envolvimento de todos no processo.

Luck (2002, p.31) destaca as principais características da gestão democrática.

Compartilhamento de autoridade; Delegação de poder; Responsabilidades assumidas em conjunto; Valorização e mobilização da sinergia de equipe; Canalização de talentos e iniciativas em todos os segmentos da organização; Compartilhamento constante e aberto de informação.

Sabe-se que em muitos momentos as escolas acabam praticando a gestão pura e simplesmente como uma administração modernizada, atualizada nos aspectos externos, mas mantendo a antiga ótica de controle de pessoas e decisões.

Conforme Vieira (2004), desde a colônia, do império até a organização da república a gestão predominante era pautada no autoritarismo, centralizadora e individualista, por este motivo algumas escolas possuem este modelo de gestão. Segundo Garske e Torres (2000), no final do século XX houve a implantação de um modelo de gestão mais democrático nas escolas, com o intuito de descentralizar e transferir responsabilidades. 
A partir dos estudos de Rosar (1999), o modelo utilizado pela administração geral para a gestão empresarial, favoreceu a influência de seus pressupostos teóricos e práticos na gestão escolar. Em razão disso, o modelo de gestão adotado nas escolas, assume características burocráticas, hierárquica, centralizada e fundamentada no controle.

No final da década de 70 começa a surgir uma gestão mais participativa dentro das escolas, propiciando uma gestão mais democrática e descentralizada, na qual as escolas passam a se configurar como um ambiente para o desenvolvimento das políticas de qualidade educativa (LUCK, 2002). Garske e Torres (2000) destacam que nesse período inicia-se uma superação do regime militar, alavancando o processo de reorganização social.

De acordo com os estudos de Garske e Torres (2000), houve um movimento à mercê de uma gestão mais participativa e menos conservadora, dessa forma, iniciaram-se políticas com a finalidade de conquistar os direitos sociais, públicos para o acesso à educação.

Dessa forma, torna-se visível que com o modelo mais democrático os gestores passam a compartilhar informações, dificuldades e é uma gestão participativa e transparente. Nesse tipo de gestão as responsabilidades são divididas e em conjunto é realizada a tomada de decisão, visando a uma educação de qualidade.

Ainda na visão de Garske e Torres (2000), para alguns Estados a gestão democrática foi instituída por meio de conselhos deliberativos e conselhos de classe, possibilitando assim eleições para gestores e construção do projeto político-pedagógico.

Libâneo (2003) salienta que na gestão democrático-participativa há divisão das responsabilidades entre os envolvidos, pois é uma gestão onde as tomadas de decisões são realizadas no coletivo. Segundo Libâneo (2003), o estilo de gestão utilizado na escola impacta diretamente nas relações humanas, pois cada indivíduo possui suas crenças, seus valores e estes devem ir ao encontro das crenças e valores da escola. Essa relação é conhecida como cultura organizacional, pois é a cultura organizacional que vai definir o tipo de liderança presente na instituição. Como exemplo de impacto da cultura organizacional dentro da instituição, podemos citar o modo como os profissionais realizam suas atividades, como estão motivados, como atendem a comunidade escolar, Saberes Pedagógicos, Criciúma, v. 3, n³, Edição Especial 2019.- Curso de Pedagogia - UNESC 
assim, pode-se destacar que a cultura organizacional impacta desde a merendeira até o gestor, todos sem exceção sofrem influências do tipo de gestão existente.

Libâneo (2003) afirma que é possível trabalhar na perspectiva de uma gestão democrática. Para isso, todos os indivíduos devem estar envolvidos com a instituição, esforçando-se para construir uma nova cultura, sendo esta pautada em novos valores, transparência e no trabalho em equipe, porém, para que isso ocorra é fundamental entender a instituição como um todo, associando-a ao seu devido papel.

Segundo Paro (2001, p.112) "escola não faz falta um chefe, ou um burocrata; à escola faz falta um colaborador, alguém que, embora tenha atribuições, compromissos e responsabilidades diante do Estado, não esteja apenas atrelando ao seu poder e colocando acima dos demais".

Para complementar, Davis e Grosbaum (2002, p. 89) afirmam:

\begin{abstract}
A presença da liderança, de cooperação, é indispensável na vida de uma equipe: alguém que tenha uma visão global da situação e que saiba onde quer chegar, incentivando no grupo a pensar e a 'por a mão na massa' para executar o que foi previsto; que aponte a direção do trabalho, apoiando o grupo durante sua execução e levando cada um a superar suas dificuldades.
\end{abstract}

O líder é essencial para toda e qualquer instituição, pois tem como papel instruir, auxiliar, desbravar os obstáculos encontrados e mostrar o caminho a ser seguido, para que desta forma todos possam caminhar na mesma direção, com vistas a superar os objetivos propostos e buscar a excelência.

Remetendo-nos aos comentários de Davis e Grosbaum (2002), entende-se que é essencial a presença da liderança e do espírito de cooperação dentro de uma equipe. Além disso, ter um gestor que tenha uma visão do todo e que saiba exatamente todas as diretrizes da instituição, onde quer chegar, para que então possa instruir e orientar os profissionais, apoiando-os durante a execução das tarefas e levando-os a superar os seus desafios.

O gestor é essencial para a instituição, no entanto, ele sozinho não consegue realizar os planejamentos, executá-los, atingir os objetivos e dar uma aprendizagem de qualidade, por este motivo é crucial compartilhar as informações para a divisão de tarefas e o trabalho em equipe.

Saberes Pedagógicos, Criciúma, v. 3, n³, Edição Especial 2019.- Curso de Pedagogia - UNESC 
Luck (2002, p. 16) dá sequência elencando os seis motivos pelos quais as escolas devem optar pela gestão democrática:

Para melhorar a qualidade pedagógica do processo educacional das escolas; Para garantir ao currículo escolar maior sentido de realidade e atualidade; Para aumentar o profissionalismo dos professores; Para combater o isolamento físico, administrativo e profissional dos diretores e professores; Para motivar o apoio comunitário às escolas; Para desenvolver objetivos comuns na comunidade escolar.

Dessa forma, ficam claros os motivos e a importância das instituições aderirem à gestão democrática, pois o processo de gestão democrática corrobora para o desenvolvimento de uma educação mais qualificada, com foco no desenvolvimento técnico-científico, cultural, social e humano.

Em suma, para consolidar uma gestão democrática torna-se necessário tomar uma posição diante da realidade e do contexto social onde a instituição está inserida. É preciso compreender de modo crítico e reflexivo o papel a ser desempenhado pelos sujeito na sociedade, de modo a contribuir com a sua formação, para que assim, possa se tornar um ser emancipado e capaz de colaborar nos processos de transformação das relações sociais.

\section{O PROJETO POLÍTICO-PEDAGÓGICO COMO INSTRUMENTO DA GESTÃO DEMOCRÁTICA}

O projeto político-pedagógico, como instrumento da gestão democrática, deve ser realizado de forma contínua e permanente, envolvendo as etapas a seguir: elaboração, execução com acompanhamento e avaliação crítica dos resultados obtidos (LIBÂNEO, 2003).

Gandin e Gandin (1999) elencam três tendências de planejamento: gerenciamento da qualidade total, estratégico e participativo. O gerenciamento da qualidade total é mais voltado para empresas. Devido a ter uma visão capitalista do negócio, este gerenciamento tem por finalidade a satisfação do cliente e a preocupação incessante na obtenção de lucros. De acordo com esta visão, planejar serve basicamente 


\section{SABERES PEDAGÓGICOS}

Revista do Curso de Graduaçāo de Pedagogia - Unesc

ISSN $2526-4559$

para solucionar os possíveis problemas que surgirem, além disso, este gerenciamento conta com dimensões técnicas e não há democracia, o poder e a autoridade pertencem a poucos e os demais profissionais participam pouco ou nada das tomadas de decisões (GANDIN; GANDIN, 1999).

Isso não quer dizer que o planejamento estratégico, assim como o da qualidade total, não possui uma visão capitalista, pelo contrário, porém está mais ligado à questão econômica. Neste caso, procura-se verificar quais são os seus respectivos pontos fortes e fracos para elaborar estratégias que gerem competitividade no mercado. O principal objetivo é manter o nível de satisfação do cliente e alavancar novas oportunidades no mercado (GANDIN; GANDIN, 1999).

Ainda na visão de Gandin e Gandin (1999), o projeto político-pedagógico, de acordo com a percepção do planejamento participativo, atua de maneira significativa para a formação cidadã. Neste planejamento o coletivo e a distribuição do poder opõem-se ao individualismo, bem como ao poder centralizado, no qual estes estão inseridos no planejamento da qualidade total e estratégico. Os autores ainda enfatizam que no planejamento participativo todos têm a liberdade de expressão, podem opinar, manifestar, avaliar, decidir e vivenciar a democracia.

Ferreira (2000) complementa afirmando que o planejamento participativo é definido como um processo que inicia pela tomada de consciência crítica e posteriormente evolui para a formulação de projeto próprio, finalizando quando há o reconhecimento da real necessidade de se organizar de maneira competente.

Para Ferreira (2000), o planejamento participativo desempenha a cooperação e o trabalho em equipe entre os indivíduos, contribuindo dessa forma para que o objetivo seja alcançado de forma mais ágil. Com o projeto político-pedagógico define-se as funções a serem desenvolvidas pela escola.

O planejamento participativo é político, segundo Gadotti (2001). Tal afirmação se dá devido ao fato de não construir um projeto sem uma direção política, por este motivo conclui-se que todo projeto pedagógico da escola é também político. O projeto políticopedagógico é um documento, no qual constam os objetivos, diretrizes e ações a serem 
desenvolvidas. Portanto, é oportuno mencionar que este projeto tem por desígnio orientar o trabalho escolar, direcionando todos os envolvidos.

Segundo Libâneo (2001, p. 125), o projeto político-pedagógico “consolida-se num documento que detalha objetivos, diretrizes e ações do processo educativo a ser desenvolvido na escola, expressando a síntese das exigências sociais e legais do sistema de ensino [...] e expectativas da comunidade escolar."

Costa (2006) enfatiza a importância de não se realizar um modelo único do projeto político-pedagógico, pois deve-se levar em consideração no momento da elaboração do projeto o contexto social em que a escola está inserida, qual é a sua realidade, suas especificidades, peculiaridades e dificuldades. Cada instituição deve realizar o seu próprio projeto, tendo como base a sua real necessidade e a do contexto em que está inserida.

Costa (2006, p. 35) elucida através de um exemplo: “[...] a sociedade está a exigir uma prática pedagógica que garanta a construção da cidadania, possibilitando a criatividade e criticidade." Através das necessidades apontadas deve-se realizar o projeto político-pedagógico, visando assim sanar tal problema.

Para compreender e realmente conseguir atender as necessidades da comunidade em que a escola está inserida, torna-se fundamental que esta obtenha um espaço de comunicação. De acordo com a visão de Costa (2006), isso gera um impacto positivo, pois ao criar espaços de participação para a comunidade na dinâmica escolar haverá a interação da comunidade com o espaço no dia a dia.

A direção não deve elaborar o projeto político-pedagógico sozinha, a escola deve realizar o trabalho em conjunto com todos os envolvidos, visando dessa forma ao trabalho em equipe e ao atendimento da real necessidade da escola e dos cidadãos. Isso remete aos comentários de Costa (2006), que ressalta a importância da realização do projeto em conjunto, isto porque para a elaboração do projeto é necessário a discussão e levantamento dos problemas, surgindo assim alternativas que possam atender as reais necessidades da instituição.

Libâneo (2001) ainda identifica que o projeto político-pedagógico é inacabado, isso porque existem diversas situações que nos circundam no mundo exterior Saberes Pedagógicos, Criciúma, v. 3, n³, Edição Especial 2019.- Curso de Pedagogia - UNESC 
(comunidade, país, mundo) que podem mudar a realidade atual em que nos encontramos, portanto, ao concluir o projeto necessita-se de revisão permanentemente e se for o caso refazê-lo.

Devem constar no projeto político-pedagógico algumas características, conforme Libâneo (2001) os descreve: princípios e objetivos comuns; delimitados por todo o conjunto escolar; definição de linha pedagógica didática comum e articulada entre professores e as formas de organização e gestão negociadas entre direção e professores. Destaca-se que após a realização do projeto tais características devem ser revisadas constantemente, devido aos motivos supramencionados.

A realização do projeto político-pedagógico é uma tarefa difícil, pois dificuldades e problemas podem ocorrer no caminho, porém, deve-se assegurar que seja implantado. Gadotti (2001) destaca os principais desafios para a elaboração do projeto: pouca experiência em ambiente democrático; estrutura vertical prevalecendo no sistema educacional; pensamento de autoridade, subordinando assim os demais, e lideranças centralizadoras.

É essencial mencionar que o projeto político-pedagógico também está previsto em leis da educação nacional. A Lei N 9.394/96, art.9 ${ }^{\circ}$, inciso I, alega que a União deve realizar o Plano Nacional de Educação, na qual orientará para elaborar o projeto políticopedagógico. A lei ainda cita em seu art. 12, inciso I, que: “Os estabelecimentos de ensino, respeitadas as normas comuns e as do seu sistema de ensino, terão a incumbência de elaborar e executar sua proposta pedagógica".

A referida lei no art. 13, inciso I, garante que também compete aos docentes participar da elaboração do projeto pedagógico da instituição de ensino. O art. 14, inciso I e II, da Lei supramencionada, aponta que:

Os sistemas definirão as normas de gestão democrática do ensino público na educação básica, de acordo com as suas peculiaridades e conforme os seguintes princípios:

I - Participação dos profissionais da educação na elaboração do projeto pedagógico da escola;

II - Participação das comunidades escolar e local em conselhos escolares ou equivalentes (BRASIL, 1996). 


\section{SABERES PEDAGÓGICOS}

Revista do Curso de Graduaçāo de Pedagogia - Unesc

ISSN 2526-4559

Anteriormente à existência da lei, segundo Costa (2006), quase não havia elaboração de projetos, e os que eram realizados aconteciam de maneira desarticulada da equipe, ou seja, apenas um membro da gestão que o realizava. $\mathrm{O}$ autor ainda complementa informando que por este motivo que os educadores não sabiam para onde deviam conduzir a educação.

Partindo desta premissa, entende-se que há necessidade da elaboração e implantação de um projeto político-pedagógico na instituição de ensino, porém, destaca-se a importância que seja elaborado em conjunto para que então sejam apontados os problemas e alavancadas alternativas e soluções, visando assim a uma boa proposta educacional.

\section{METODOLOGIA, APRESENTAÇÃO E ANÁLISE DE DADOS}

O presente trabalho tem como propósito discorrer sobre a gestão democrática e a formação para a cidadania. Para tanto, foi aplicado um questionário com os gestores de três escolas da rede pública municipal da cidade de Criciúma/SC. Quanto aos fins de investigação, o presente estudo caracteriza-se como uma pesquisa qualitativa e descritiva.

A pesquisa qualitativa tem por finalidade entender fatos, acontecimentos e opiniões através da coleta de dados, sendo que esta coleta é realizada através de entrevistas, questionários abertos e observações que não utilizem numerais como base. Outra peculiaridade importante da pesquisa qualitativa é que o entrevistador não pode expressar e permitir que suas opiniões, julgamentos, crenças ou preconceitos contaminem os dados e a pesquisa realizada (GOLDENBERG, 1997).

Já a pesquisa descritiva, segundo Jung (2004), visa encontrar e identificar a frequência em que os acontecimentos ocorrem, além de suas particularidades. E, ao contrário da pesquisa qualitativa, a pesquisa descritiva possui a interferência do entrevistador.

Com o propósito de coletar dados, a pesquisa foi realizada com a participação de três gestores de escolas diferentes da rede pública municipal. As entrevistas foram previamente agendadas, de acordo com a disponibilidade de cada gestor. O tema da Saberes Pedagógicos, Criciúma, v. 3, n³, Edição Especial 2019.- Curso de Pedagogia - UNESC 


\section{SABERES PEDAGÓGICOS}

Revista do Curso de Graduaçūo de Pedagogia - Unesc

ISSN 2526-4559

pesquisa foi previamente apresentado aos entrevistados e posteriormente eles assinaram o termo de consentimento de participação da pesquisa. Por uma questão de ética, os nomes das escolas e dos entrevistados não serão apresentados, ficando assim os gestores identificados como entrevistados A, B, C, respectivamente.

$\mathrm{Na}$ sequência ao roteiro de perguntas, buscou-se identificar quais os projetos e instrumentos são utilizados pela gestão escolar; qual o entendimento que o gestor possui referente à função social da escola e para finalizar foi questionado se o gestor considera importante a participação da comunidade na gestão da escola e de que forma ocorre esse processo. Após a coleta dos dados, iniciou-se a análise dos resultados, tendo como base a fundamentação teórica de cada autor estudado. Os entrevistados têm mais de dois anos de experiência no âmbito escolar, ressalta-se que este questionamento não teve relevância para fins de análises, pois todos os entrevistados possuem aproximadamente o mesmo tempo de experiência.

Um dos questionamentos realizados na pesquisa foi sobre a formação acadêmica do gestor e se tem alguma formação na área de gestão. Tais questionamentos são relevantes e oportunos para identificar se o gestor possui algum embasamento teórico acerca da gestão escolar, tendo em vista ser fundamental boas práticas de gestão devido aos impactos que podem ser ocasionados no processo de ensino e aprendizagem.

Como resultado obtido temos: o entrevistado A possui licenciatura em Matemática, já o entrevistado B tem graduação e pós-graduação em Artes Plásticas e por fim o entrevistado $C$ é graduado em Pedagogia e possui especialização e mestrado na área da Educação.

Quanto ao curso em gestão, que tem por finalidade auxiliar os gestores na administração, o entrevistado A não possui e não considera pertinente a realização deste. Já os entrevistados B e C possuem curso na área de gestão. O resultado obtido, de uma maneira geral, é satisfatório, porém, ainda preocupante que um dos entrevistados esteja ocupando um cargo de gestão e não acredite que seja importante investir em cursos para se aperfeiçoar na sua área de atuação.

Destaca-se ainda que é possível identificar através das perguntas supramencionadas que o grau de instrução influência diretamente nas respostas da Saberes Pedagógicos, Criciúma, v. 3, nº3, Edição Especial 2019.- Curso de Pedagogia - UNESC 
presente pesquisa, pois o entrevistado $\mathrm{C}$ respondeu ao questionário com maior coesão e embasamento teórico.

Como já mencionando, em diversos momentos deste trabalho, destacamos que a função social da escola é crucial para a boa formação acadêmica e cidadã do indivíduo. Partindo desse pressuposto, foi questionado aos entrevistados qual o entendimento que possuem a respeito da função social da escola.

Como respostas obtidas, identificamos que o entrevistado A acredita que a escola deve servir à resolução de problemas e prestar assistência social. O entrevistado B apontou que se deve olhar a escola como um todo, embora seja uma tarefa árdua, devido ao fato de ter outros afazeres, e, como consequência, ressaltou que muitas vezes fazer da escola um lugar de construção social é deixado de lado. O entrevistado C citou que a escola tem a função social de produzir conhecimento científico aos alunos.

Mediante as respostas supramencionadas, percebe-se a falta de entendimento sobre o significado da função social da escola. É importante frisar que é compromisso da escola ajudar na formação integral dos sujeitos, de modo a atuarem na sociedade de forma crítica e participativa. Isso remete aos comentários de Saviani (1997), o qual menciona a importância da escola no que diz respeito às suas funções, a fim de desempenhar ações condizentes às atribuições de sua competência.

Ainda de acordo com o autor, a instituição escolar possui como principal função a socialização do saber sistematizado, ou seja, a função de educar sistematicamente. Saviani (1997) ainda cita que é fundamental que a escola resgate a sua importância e com isso reorganize todo o trabalho educativo, não esquecendo de considerar o saber sistematizado, pois é a partir dele que se define a especificidade da educação escolar.

Conforme a Lei $\mathrm{N}^{\circ}$ 9.394/96, Art.32, os objetivos do Ensino Fundamental de nove anos a serem alcançados são:

I - O desenvolvimento da capacidade de aprender, tendo como meios básicos o pleno domínio da leitura, da escrita e do cálculo;

II - A compreensão do ambiente natural e social, do sistema político, da tecnologia, das artes e dos valores em que se fundamentam a sociedade;

III - O desenvolvimento da capacidade de aprendizagem, tendo em vista a aquisição de conhecimento e habilidades e a formação de atitudes e valores;

Saberes Pedagógicos, Criciúma, v. 3, n³ 3, Edição Especial 2019.- Curso de Pedagogia - UNESC 
IV - O fortalecimento dos vínculos de família, dos laços de solidariedade humana e de tolerância recíproca em que se assenta a vida social (BRASIL, 1996).

A educação por si só não assegura a justiça social, o fim da violência, a erradicação da discriminação social e o respeito ao meio ambiente, no entanto, trabalha em prol do desenvolvimento integral do cidadão, tornando a sociedade mais igualitária, solidária e integrada (MELLO,2005).

Com relação à importância da participação da comunidade educativa na gestão da escola, o entrevistado A afirmou que é importante ter uma gestão democrática, ouvir todos, porém, torna-se difícil administrar a opinião de todos devido às diversidades nas opiniões, portanto o entrevistado disse ouvir todas as opiniões, mas quem toma a decisão é apenas ele.

O entrevistado B alegou que possui uma gestão democrática, onde há a participação da comunidade, e que como gestor orienta, conversa com os professores, pais e alunos objetivando entender suas dificuldades para posteriormente saná-los. O entrevistado C também mencionou ter uma gestão democrática e que acredita na importância da participação de todos para a construção de cidadãos melhores, no entanto, destaca que isso pode ocorrer desde que haja limites, no qual cada um respeite seus espaços.

Pode-se verificar que todos os gestores afirmam ser importante a participação da comunidade na gestão, mas de acordo com as respostas percebe-se um certo receio por parte dos gestores que realmente a comunidade esteja presente e tenha voz ativa para auxiliar nas tomadas de decisões.

A Lei $\mathrm{N}^{\circ}$ 9.394/96, art. 13, inciso I, garante que também compete aos docentes participar da elaboração do projeto pedagógico da instituição de ensino (BRASIL, 1996). $\mathrm{O}$ art. 14, inciso I e II, da Lei supramencionada, aponta que:

\footnotetext{
Os sistemas definirão as normas de gestão democrática do ensino público na educação básica, de acordo com as suas peculiaridades e conforme os seguintes princípios:

I - Participação dos profissionais da educação na elaboração do projeto pedagógico da escola;

II - Participação das comunidades escolar e local em conselhos escolares ou equivalentes (BRASIL, 1996).
}

Saberes Pedagógicos, Criciúma, v. 3, n³3, Edição Especial 2019.- Curso de Pedagogia - UNESC 


\section{SABERES PEDAGÓGICOS}

Revista do Curso de Graduaçāo de Pedagogia - Unesc

ISSN $2526-4559$

Ao serem questionados de que forma ocorre o processo de participação na escola, o entrevistado A alegou que a participação ocorre de maneira informal, onde suas “portas" estão sempre abertas para ouvir todos e a decisão quem toma é o gestor. Já o entrevistado B citou que a participação ocorre através do grêmio estudantil, APP e conselho escolar. $\mathrm{O}$ entrevistado $\mathrm{C}$ afirmou que a participação ocorre através das entregas de boletins, questionários que são encaminhados para casa, reuniões e eventos que são realizados, pois dessa forma torna-se mais fácil sanar os problemas e tomar as decisões cabíveis.

Com este questionamento, nota-se que realmente existe um receio por parte dos gestores pesquisados, receio este percebido no questionamento anterior, pois eles incluem a sociedade na participação de ações informais, em nenhum momento foi mencionado projetos e reuniões estratégicas.

Quando questionados sobre a participação na elaboração do projeto políticopedagógico, o entrevistado A alegou que o projeto político-pedagógico é realizado apenas porque é previsto por lei. O projeto é realizado e não há participação e cooperação para a realização, sendo este posteriormente engavetado. O entrevistado B afirmou que a comunidade não participa da realização do projeto político-pedagógico (PPP), e o projeto é realizado apenas pelo gestor e os professores. Já o entrevistado $\mathrm{C}$ mencionou que a comunidade e todos os envolvidos participam da realização do projeto políticopedagógico.

Todos os entrevistados responderam que trabalham na perspectiva da gestão democrática, porém esta resposta na verdade é contraditória, pois nem todos permite m que a comunidade participe do projeto político-pedagógico. Pode-se perceber que para os entrevistados A e B a gestão é democrática apenas quando é uma decisão informal, quando a decisão é estratégica quem decide é apenas o gestor, e no caso do entrevisto B os professores também participam.

Conforme Luck (2002), para que uma escola possa obter o sucesso, todos devem caminhar juntos rumo aos mesmos objetivos, sendo indispensável a participação dos funcionários, professores e comunidade na construção do projeto político-pedagógico. 


\section{SABERES PEDAGÓGICOS}

Revista do Curso de Graduaçāo de Pedagogia - Unesc

ISSN 2526-4559

O projeto político-pedagógico é “[...] um guia de orientação para o planejamento do processo de ensino (LIBÂNEO, 2000, p. 230)."

Para finalizar os questionamentos foi perguntado aos entrevistados quais projetos ou instrumentos são utilizados pela gestão escolar na formação para a cidadania. O entrevistado A disse que não há um projeto estruturado, pois papéis e projetos na visão do entrevistado são "besteiras". Ele ainda afirmou que projetos não funcionam e que as pessoas falam muito e agem pouco, portanto o instrumento utilizado é o bom relacionamento, a afetividade e estar sempre disposto a ouvir.

O entrevistado B também mencionou que não possui um projeto, mas como instrumento utilizado para a boa formação para a cidadania, é através de cobranças rigorosas no dia-a-dia com as responsabilidades que os alunos possuem, como por exemplo: horário de entrada e saída na sala de aula, uniforme e trabalhos entregues em dia. E o entrevistado C também não possui o projeto, mas observa a partir das falas dos alunos as ações que deve tomar.

Conclui-se então que nenhuma das escolas pesquisadas possui algum tipo de elemento ou instrumento estruturado e realmente voltado para a formação cidadã, porém entende-se que esta questão requer um novo olhar por parte dos gestores pesquisados, pois a escola tem um papel fundamental, como instituição social, para contribuir no crescimento e na construção da cidadania. Para isso é necessário que a escola tenha planejamento e ferramentas que possibilitem o conhecimento, informação e práticas vivenciais que favoreçam a formação cidadã (SAVIANI, 1997).

A gestão democrática possui em seus princípios e metas a formação para a cidadania. Isso acontece quando a escola cria vínculos com a comunidade, se compromete com a aprendizagem dos educandos e busca incessantemente a qualidade dos seus processos, sejam eles administrativos ou pedagógicos.

\section{CONCLUSÃO}

$\mathrm{O}$ primeiro aspecto relacionado às considerações finais está vinculado às perguntas da pesquisa que induziram a este estudo. O propósito desta investigação foi Saberes Pedagógicos, Criciúma, v. 3, nº3, Edição Especial 2019.- Curso de Pedagogia - UNESC 
analisar o papel da gestão democrática na formação para a cidadania. Considerando determinadas alíneas mencionadas nas descrições desta pesquisa, observa-se que a gestão democrática é um meio que propicia e auxilia na formação para a cidadania.

Tal gestão contribui de forma eficiente para a construção do projeto político pedagógico, instrumento que norteia as ações da gestão, no âmbito das áreas pedagógica e administrativa, em direção à consecução dos objetivos institucionais.

Considerando as premissas desta pesquisa, percebeu-se que na maioria das escolas pesquisadas a gestão democrática ocorre quando é uma decisão informal, que seja de pouca responsabilidade, já quando é uma decisão que gera maior impacto, como por exemplo a elaboração do projeto político-pedagógico, quem faz é apenas o gestor ou o gestor com os professores, sem a participação dos pais e alunos.

Portanto, a maioria dos entrevistados considera o projeto político-pedagógico um roteiro elaborado para dar cumprimento às exigências previstas em lei, assumindo, assim, um caráter técnico e burocrático. Também ficou evidenciado através da pesquisa que a maioria das escolas entrevistadas desenvolve algumas ações, dando assim cumprimento à função social, no entanto, são ações pontuais, ou seja, ocorrem apenas de maneira ocasional.

Nenhuma das pesquisadas possui algum tipo de instrumento estruturado e realmente voltado para a formação da cidadania. A escola tem um papel fundamental, como instituição social, para contribuir no crescimento e na construção da cidadania, para isso é necessário que tenha planejamento e ferramentas que possibilitem o conhecimento, informação e práticas vivenciais que favoreçam a formação cidadã (SAVIANI, 1997).

Partindo desse pressuposto, a gestão democrática constitui-se num grande desafio, pois não é uma tarefa simples e fácil. Embora a legislação defina o modelo de gestão democrática como premissa para as ações da escola, ainda se percebe modelos de gestão autoritários e centralizadores. Assim, esta pesquisa não é um mero trabalho com um fim em si mesmo, pois a intenção é suscitar reflexões acerca da gestão escolar numa perspectiva democrática com vistas a contribuir com o processo de construção da gestão escolar democrática e responsável pela formação para a cidadania. 


\section{SABERES PEDAGÓGICOS}

Revista do Curso de Graduaçāo de Pedagogia - Unesc

ISSN 2526-4559

\section{REFERÊNCIAS}

ARANHA, Maria Lúcia de Arruda. História da educação e da pedagogia: geral e Brasil. 3. ed. São Paulo: Moderna, 2006.

ARROYO, Miguel. Educação e exclusão da cidadania. In: BUFFA, Ester; ARROYO, Miguel; NOSELLA, Paolo. Educação e cidadania: quem educa o cidadão? 14. ed. São Paulo: Cortez, 2010. P. 35-98.

BORDIGNON, Genuino; GRACINDO, Regina Vinhaes. Gestão da educação: o município e a escola. In: FERREIRA, Naura Syria Carapeto; AGUIAR, Márcia Angela da S. (Orgs.). Gestão da educação: impasses, perspectivas e compromissos. 3. ed. São Paulo: Cortez, 2001. P. 147-176.

BRASIL, Constituição (1988). Constituição da república federativa do Brasil.Brasília, DF: Senado federal, 1988.

.Lei $\mathbf{N}^{0}$ 9.394, de $2^{\circ}$ de dezembro de 1996. Estabelece as diretrizes da educação nacional. Brasília: 1996.

COSTA, Gisele Maria Tonin da. Projeto político-pedagógico: uma perspectiva de identidade no exercício da autonomia e a construção da cidadania. Rei: Revista de Educação do Ideau, Getúlio Vargas, RS, v. 1, n.1, p. 33-44, ago./2006.

COVRE, Maria de Lourdes Manzini. O que é cidadania. 3. ed. São Paulo: Brasilense, 1998.

DAVIS, Cláudia; GROSBAUM, Marta Wolak. Sucesso de todos, compromisso da escola. In: VIEIRA, Sofia Lerche. (Org.). Gestão da escola: desafios a enfrentar. Rio de Janeiro: DP \& A, 2002. p. 85-102.

ESTÊVÃO, Carlos A. Vilar. Gestão Educacional e formação. In: FERREIRA, Naura Syira Carapeto (Org.); MACHADO, Lourdes Marcelino. Política e Gestão da Educação: Dois Olhares. Rio de Janeiro: DP\&A, 2002. p.83-106.

FERREIRA, Naura Syria Carapeto. Gestão democrática da educação para uma formação humana: Conceitos e possibilidades. In: LUCK, Heloisa (Org.). Em aberto: Gestão escolar e formação de gestores. Brasília: O Instituto, v. 17, nº 72, fev./jun., 2000. p. 167176.

GADOTTI, Moacir. Projeto político-pedagógico da escola: fundamentos para a sua realização. In: GADOTTI, Moacir; ROMÃO, José E. (orgs.). Autonomia da escola: princípios e propostas. 4. ed. São Paulo: Instituto Paulo Freire, 2001. p. 33-42. 


\section{SABERES PEDAGÓGICOS}

Revista do Curso de Graduaçāo de Pedagogia - Unesc

ISSN 2526-4559

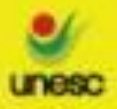

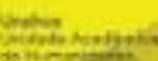

GANDIN, Danilo; GANDIN, Luís Armando. Temas para um projeto políticopedagógico. Rio de Janeiro: Ed. Vozes, 1999.

GARSKE, Lindalva Maria N.; TORRES, Ártemis. Diretores de escola: o desacerto com a democracia. In: LUCK, Heloísa (Org.). Em aberto: Gestão escolar e formação de gestores. Brasília: O Instituto, v. 17, n. 17, nº 72, fev./jun., 2000. p. 60-70.

GOLDENBERG, M. A arte de pesquisar. Rio de Janeiro: Record, 1997.

JUNG, Carlos Fernando. Metodologia para pesquisa \& desenvolvimento: aplicada a novas tecnologias, produtos e processos. Rio de Janeiro: Axcel Books do Brasil, 2004.

LIBÂNEO, José Carlos. O planejamento escolar e o projeto pedagógico na prática escolar. In: Organização e gestão da escola: teoria e prática. 4. ed. Goiânia: Alternativa, 2001. p. 121-170.

Organização e gestão da escola: teoria e prática. Goiânia: Alternativa, 2003.

LUCK, Heloísa. et. al. Uma abordagem participativa para a gestão escola. In:

escola participativa, o trabalho do gestor escolar. Rio de Janeiro: DP\&A, 2002. p. 1358 .

MELLO, Guiomar Namo de. Transformação produtiva com equidade e solidariedade. In:

Cidadania e competitividade: desafios educacionais do terceiro milênio. 10. ed.

São Paulo: Cortez, 2005. p. 29-43.

PARO, Vitor Henrique. Gestão democrática da escola pública. $3^{\text {a }}$ Edição. São Paulo: Ática, 2001.

ROSAR, Maria de Fátima Felix. A dialética entre a concepção e a prática da gestão democrática no âmbito da educação básica no Brasil. Educ. Soc., Campinas, v. 20, n. 69, 1999. Disponível em:

<http://www.scielo.br/scielo.php?script=sci_arttext\&pid=S0101 -

73301999000400008\&Ing=pt\&nrm=iso >. Acesso em: 21 abril. 2018.

SAVIANI, Demerval. Pedagogia histórico-crítica: primeiras aproximações. 6. ed. São Paulo: Autores Associados, 1997.

VIEIRA, Sofia Lerche. Escola: Função social, gestão e política educacional. In: AGUIAR, Márcia Ângela da S (Orgs.); FERREIRA, Naura Syria Carapeto Ferreira. Gestão da educação: Impasses, perspectivas e compromissos. 4 Edição. São Paulo: Cortez, 2004. p. 129-145.

Recebido: 11/06/2019

Aprovado: 01/08/2019

Publicado: 20/09/2019

Saberes Pedagógicos, Criciúma, v. 3, n³, Edição Especial 2019.- Curso de Pedagogia - UNESC 